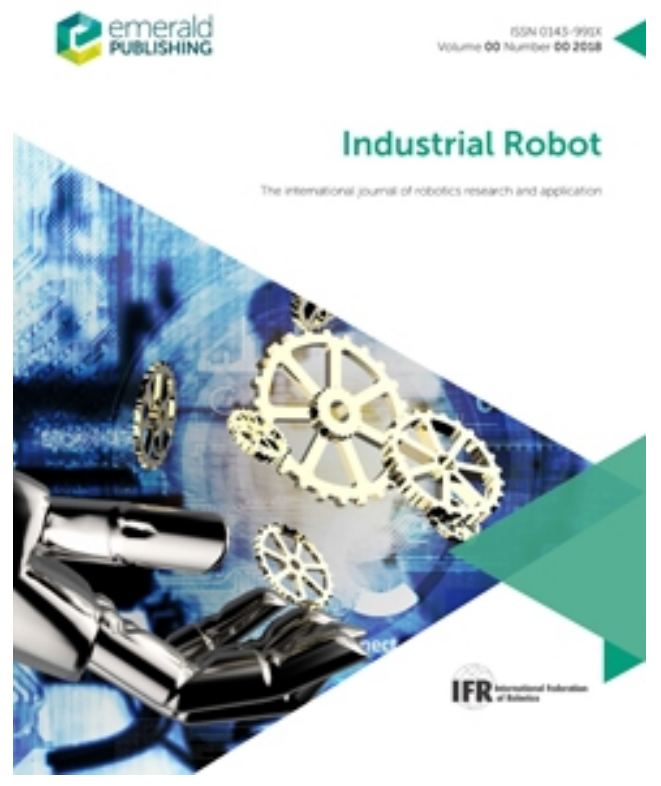

\title{
Workspace analysis of Cartesian robot system for kiwifruit harvesting
}

\begin{tabular}{|r|l|}
\hline Journal: & Industrial Robot \\
\hline Manuscript ID & IR-12-2019-0255.R3 \\
\hline Manuscript Type: & Original Manuscript \\
\hline Keywords: & Cartesian robot, articulated robot, workspace, kiwifruits, harvesting \\
\hline \multicolumn{2}{|l}{} \\
\hline
\end{tabular}

\section{SCHOLARONE} Manuscripts 


\title{
Workspace analysis of Cartesian robot system for kiwifruit harvesting (Revised version)
}

\begin{abstract}
Purpose - This article aims to investigate if a Cartesian robot system for kiwifruit harvesting works more effectively and efficiently than an articulated robot system. Robot is a key component in agricultural automation. For instance, multiple robot arm system has been developed for kiwifruit harvesting recently because of the significant labour shortage issue. The industrial robots for factory automation usually have articulated configuration which is suitable for the tasks in manufacturing and production environment. However, this articulated configuration may not fit for agricultural application due to the large outdoor environment.
\end{abstract}

Design/methodology/approach - The kiwifruit harvesting tasks are completed step by step so that the robot workspace covers the canopy completely. A two-arm, Cartesian kiwifruit harvesting robot system and several field experiments are developed for the investigation. The harvest cycle time of the Cartesian robot system is compared to that of an articulated robot system. The difference is analysed based on the workspace geometries of these two robot configurations.

Findings - It is found that the kiwifruit harvesting productivity is increased by using a multiple robot system with Cartesian configuration owing to its regular workspace geometry.

Originality/value - Articulated robot is a common configuration for manufacturing due to its simple structure and the relatively static factory environment. Most of the agricultural robotics researches employ single articulated robot for their implementation. This article pinpoints how the workspace of a multiple robot system affects the harvest cycle time for kiwifruit harvesting in a pergola style kiwifruit orchard.

Keywords: Cartesian robot, articulated robot, workspace, kiwifruits, harvesting

\section{Introduction}

An industrial manipulator is usually an articulated robotic arm with rotational axes. However, it is not necessarily optimal for every task. Without considering the end-effector orientation, a three-axis arm provides enough degrees of freedom necessary for 3D positioning. This approach is used in developing a three-axis planar articulated robot arm with an autonomous mobile platform for picking kiwifruit (Williams et al 2019). Nevertheless, there are speculative avenues for improving this configuration, such as the workspace efficiency of the robot arms and harvesting efficiency of end-effector.

If the workspace geometry of a robot conforms to the canopy geometry, the robot arm reachability to complete the task will be high. Hence, a kiwifruit is reachable if its position in the canopy is inside the workspace of a robot arm. The harvesting will then be more efficient as it does not need to move the robot base frequently to include the fruit into its workspace. However, different configurations (such as articulated robot and Cartesian robot) yield different workspace geometry.

This article investigates the effects of robot arm workspace geometry on a multiple robot arm system for kiwifruit harvesting. It is hoped that the investigation of robot configuration will promote the kiwifruit harvesting automation for alleviating current labour shortage. 


\section{Related work}

Many agricultural tasks such as harvesting, pollination, crop-maintenance etc are typically repetitive. In order to be economically competitive with equivalent human labour, it is beneficial for an agricultural machine to complete these tasks effectively, efficiently and reliably within environmentally challenging conditions.

A harvesting robot typically consists of three main components (Bachche 2015):

1. A mobile platform for movement.

2. A recognition system for fruit identification and location.

3. A manipulator and an end-effector for fruit harvesting.

A comprehensive review on 50 robotic harvesting systems finds that the average harvesting robot will locate $85 \%$ of the fruit, detach $75 \%$, harvest $66 \%$ and damage $5 \%$ (Bac et al 2014).

Harvest cycle time is a metric for measuring the robot performance. This is the time taken to locate, detach and harvest the fruit. The average harvest cycle time for published harvesting robot systems in 2014 is 33 seconds (Bac et al 2014). Much of the technical challenges involved in robotic harvesting are well known (Sarig 1993, Li, Lee and Hsu 2011, Kapach et al 2012), and mostly arise from task complexity in a dynamic environment.

One approach to improve the harvest cycle times is to optimize the hardware configuration. A cucumber harvesting robot has been developed (Henten et al. 2009). However, it is acknowledged that the original manipulator kinematic structure is far from ideal. One study proposes the design optimization and simulation of the kinematic structure of an eggplant picking robot (Han et al. 2007). Another study (Baur 2014) covers several topics essential for the design of a modular pepper harvesting and precision spraying robot manipulator.

Investigation on the kinematic design for this system is shown (Baur et al. 2012) by analysing various high degree of freedom workspace combinations in relation to the task space.

Another methodology (Bloch et al. 2017) for optimizing the kinematics and location of an agricultural robotic arm is presented by considering the characteristic environment that approximates the actual orchard environment.

In spite of the aforementioned contributions, the majority of robotic harvesting systems focus their research on identification and manipulator control instead of optimizing the hardware configuration. There are many published robotic harvesting systems across different crop types since 2018 such as cucumber (van Henten et al. 2003), sweet pepper (Bac et al. 2017), radicchio (Foglia and Reina2006), tomato (Li et al 2017), strawberry (Hayashi et al 2014), apples (Silwal et al 2017) and kiwifruit (Mu et al 2020).

However, explicit justifications for adopting certain kinematic structures are found only on single robotic arm harvesting systems and most of the robot arms employed are articulated robots. In order to raise the efficiency and effectiveness of employing robots for harvesting, multiple robots should be considered. For instance, a robot with four articulated picking arms (Scaefe 2009) is developed for harvesting kiwifruits. Nevertheless, if the robot configuration for fruit harvesting is not efficient and effective, then this insufficiency is just magnified for a multiple robot system. As a result, this arrives at the research question that how the robot arm workspace affects the kiwifruit harvesting, especially, when multiple robot system is used. 


\section{Harvest cycle time and workspace geometry}

Most of the kiwifruit in an orchard are grown in a rectangular array with the vines trained onto a pergola structure so that the fruit hang across the canopy as shown in Figure 1. The canopy is described as a Cartesian system with $x$ axis along the length and $y$ axis along the width of the array of fruit trees.

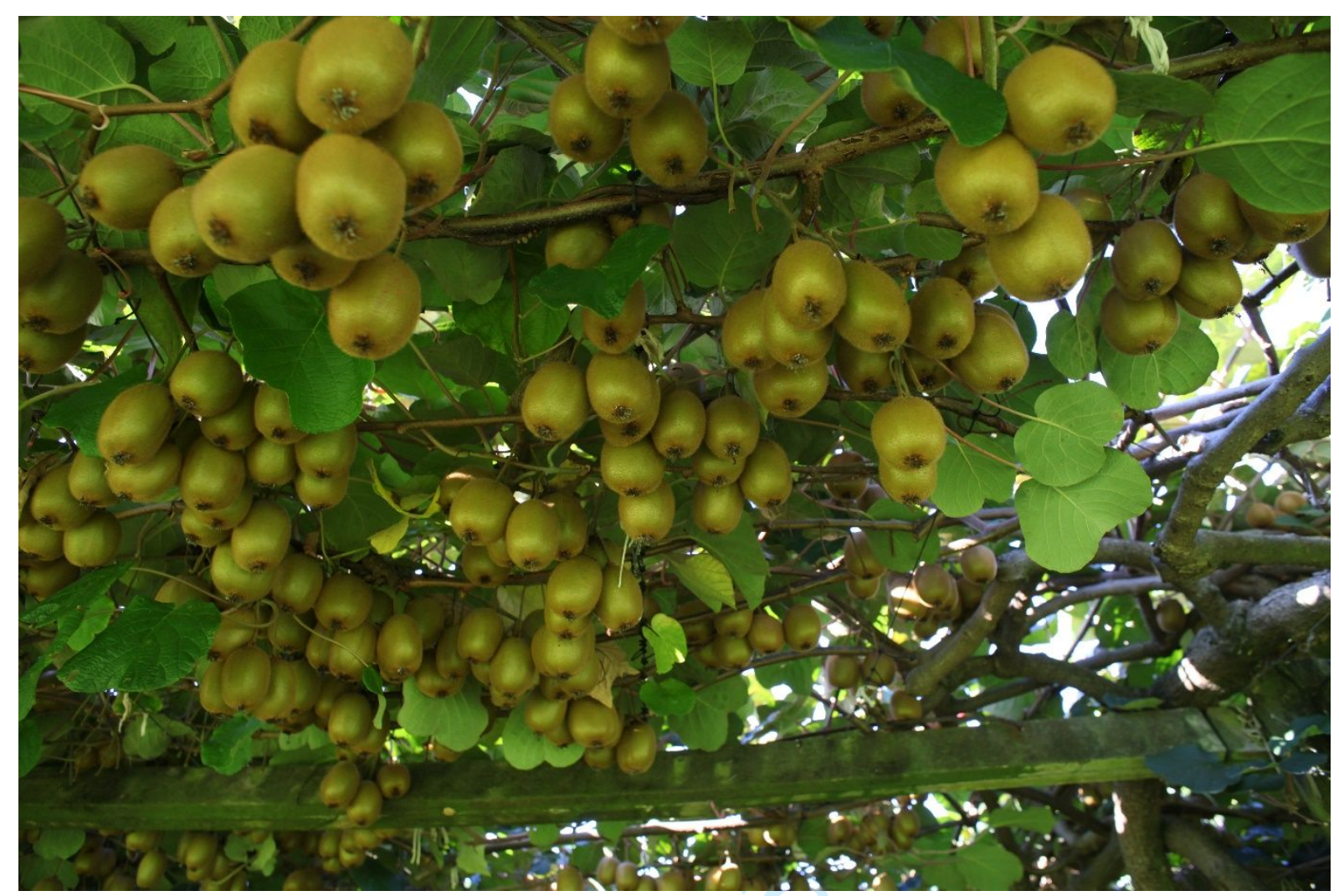

Figure 1. Kiwifruit in the canopy.

The harvesting process is assumed to be performed by a robot system with $N_{\text {arms }}$ arms. It also has a machine vision system for locating the kiwifruit. Due to the large size of kiwifruit orchard, the harvesting process performed by the robot system is split into rows of steps. Each discrete harvesting step is executed longitudinally along a row. The process is completed row by row laterally.

A step consists of the following processes:

i. The mobile platform starts moving from one location to another location

ii. The kiwifruit are detected and located by the vision system when the platform arrives at a specific location

iii. The located kiwifruit are all harvested by the robot arms

A fruit scheduler (Barnett 2018) is implemented in the robot system to read the fruit locations, allocate the fruit to the robot arms and determine the picking order.

Because of the non-uniform fruit distribution, cluster growing style and fruit location relative to the robot arm position (as these factors affect the picking order and robot arm availability), 
the work distributed to each robot arm by the fruit scheduler may not balance. A parameter termed work distribution $W_{D}$ is introduced to reflect the imbalance of work distribution among the robot arms. It is defined as

$W_{D}=\frac{W_{\text {parity }}}{W_{\text {busiest }}}$

where $W_{\text {parity }}$ is the average number of fruits which should be harvested by a robot arm and $W_{\text {busiest }}$ is the maximum number of fruits harvested by one robot arm

The average harvest cycle time $t_{H C T}$ is the average time required to harvest a kiwifruit, which is

$t_{H C T}=\frac{N_{\text {steps }}\left(t_{\text {move }}+t_{\text {locate }}\right)}{N_{\text {fruits }}}+\frac{t_{\text {sub }- \text { step }}}{N_{\text {arms }} \cdot W_{D}}$.

where $t_{\text {move }}$ and $t_{\text {locate }}$ are the average times for the autonomous robotic system to move from its current position to the position of next step, detect and locate the fruit in each step respectively. $t_{\text {sub-step }}$ is the sub-step time taken for a robot arm to detach a fruit, and then move to the next fruit. $N_{\text {steps }}$ is the number of steps to completely harvest $N_{\text {fruits }}$ kiwifruits.

At each step, a space is obtained by intersecting the robot workspace with the canopy, which contains the fruit at the reachable positions. These fruit will be harvested. For each row, the volume of the space in the first step and the subsequent steps are termed harvestable volume $V_{h}$ and step advance volume $V_{a}$ respectively such that

$V_{a} \leq V_{h}$

Consider the average volumetric density of fruit $\rho$ (number of fruit per unit volume) within an orchard, the number of fruits per step ratio $\frac{N_{\text {fruits }}}{N_{\text {steps }}}$ is approximated as

$\frac{N_{\text {fruits }}}{N_{\text {steps }}}=\rho \cdot V_{a}$

Thus, equation (2) can be rewritten as

$t_{H C T}=\frac{t_{\text {move }}+t_{\text {locate }}}{\rho \cdot V_{a}}+\frac{t_{\text {sub }- \text { step }}}{N_{\text {arms }} \cdot W_{D}}$.

As a result, the harvest cycle time can be estimated based on the average volumetric density of fruit in an orchard. In order to shorten the harvest cycle time, the step advance volume should be increased by having large step advance distance.

Figure 2 depicts the difference in step advance volume covered by a Cartesian robot and an articulated robot. Since the workspace geometry of a Cartesian robot is rectangular shape, the step advance volume equals to its harvestable volume. On the other hand, the workspace geometry of an articulated robot is irregular shape; the step advance volume is less than its harvestable volume. As a result, a Cartesian robot has a larger step advance volume than that 
of an articulated robot if both possess the same harvestable volume or a Cartesian robot has larger harvestable volume than that of an articulated robot. Since the union of all the harvestable volume of each step must cover the complete canopy (task space), employing a Cartesian robot for fruit harvesting should have less number of steps. Of course, the step advance volume of an articulated robot can be larger than that of a Cartesian robot if its harvestable volume is large enough. However, this implies a comparatively large workspace or robot dimensions.

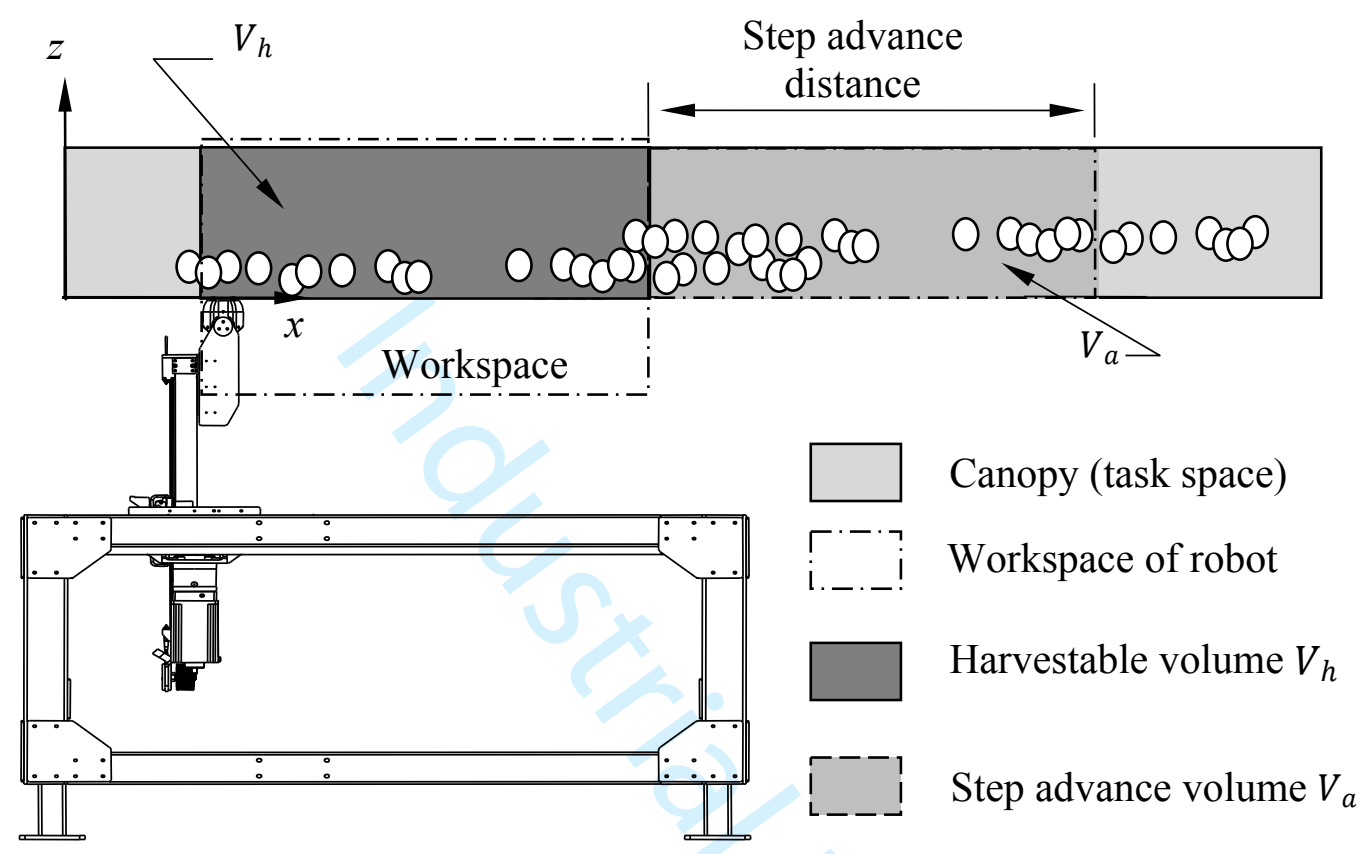

(a) A Cartesian robot

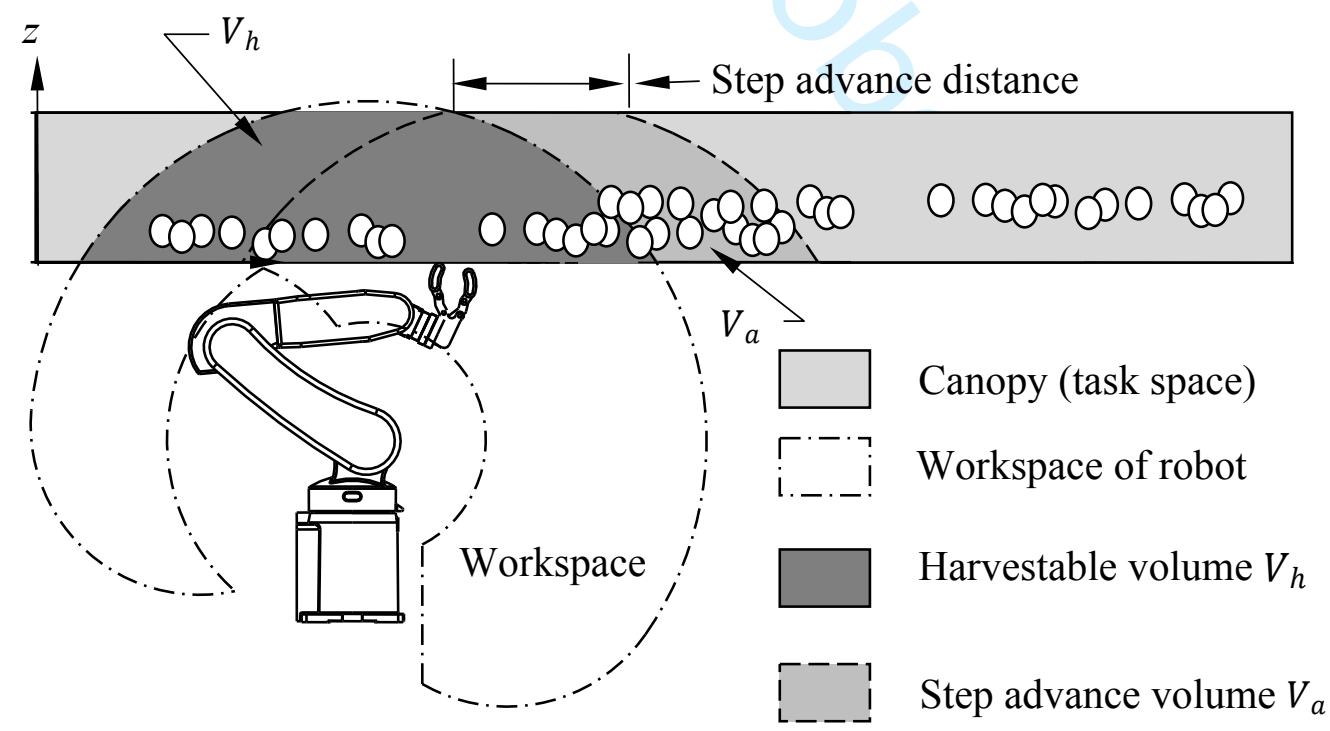

(b) An articulated robot

Figure 2. Workspace geometry of robot arm. 


\section{Field tests}

The field tests aim to investigate the kiwifruit harvesting performance of a Cartesian robot. Figure 3 shows a two-arm, Cartesian kiwifruit harvesting robot, which is developed as a research platform to perform the workspace analysis and investigate how it affects the kiwifruit harvesting comparing to an articulated robotic system.

Each Cartesian robot-arm $i$ has $x_{i}, y_{i}$ and $z_{i}$-axis $(i=1,2)$. Axis $x_{1}$ and $x_{2}$ for both robot arms share a common axis such that they can move synchronously throughout a resultant workspace.

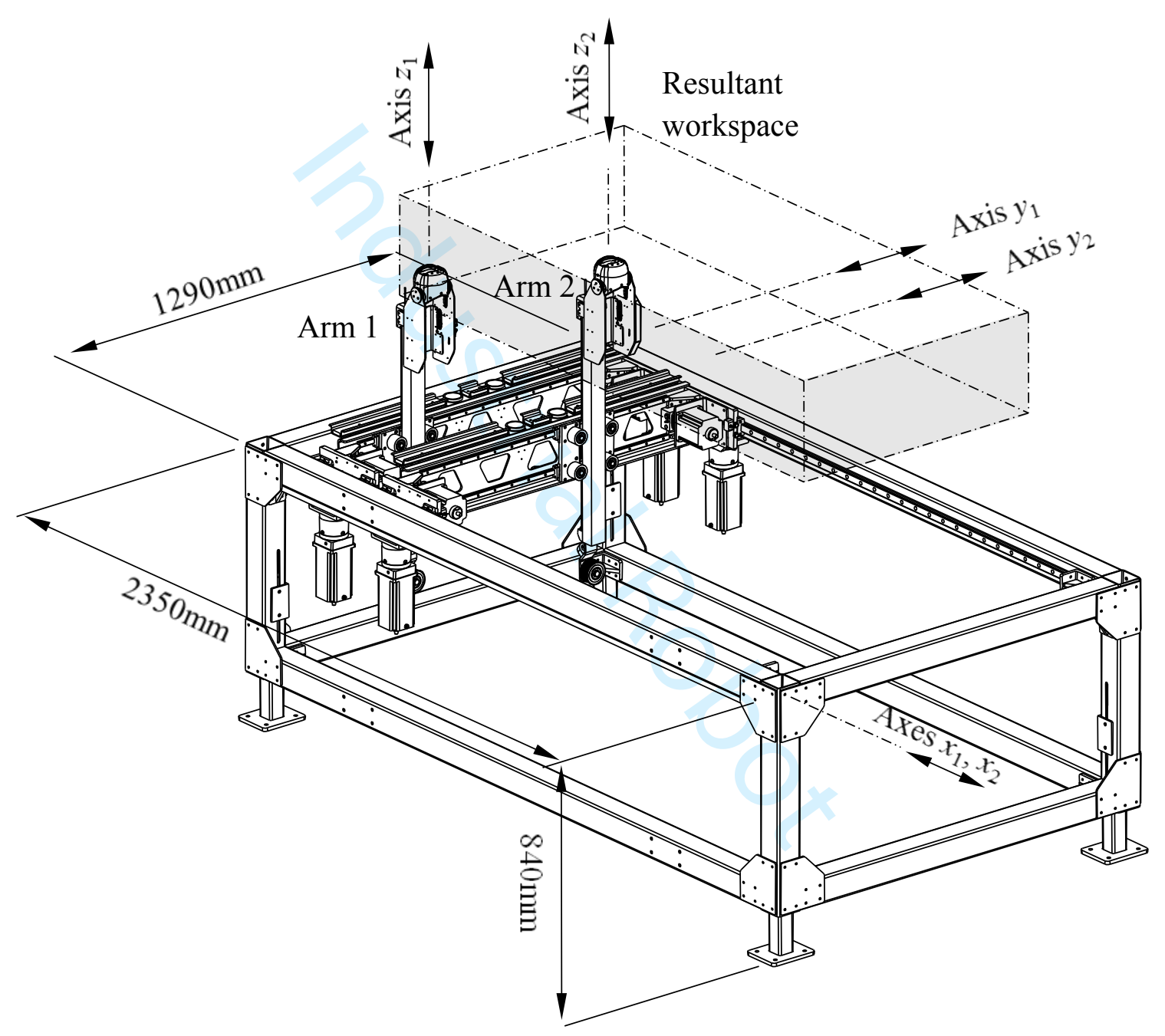

Figure 3. A Cartesian robot system with two arms and its resultant workspace.

The limits for axis $x, y$ and $z$ are $1500 \mathrm{~mm}, 650 \mathrm{~mm}$ and $450 \mathrm{~mm}$ respectively, which yields a resultant rectangular workspace volume as shown. Figure 4 shows the multiple robot systems in the orchard. 


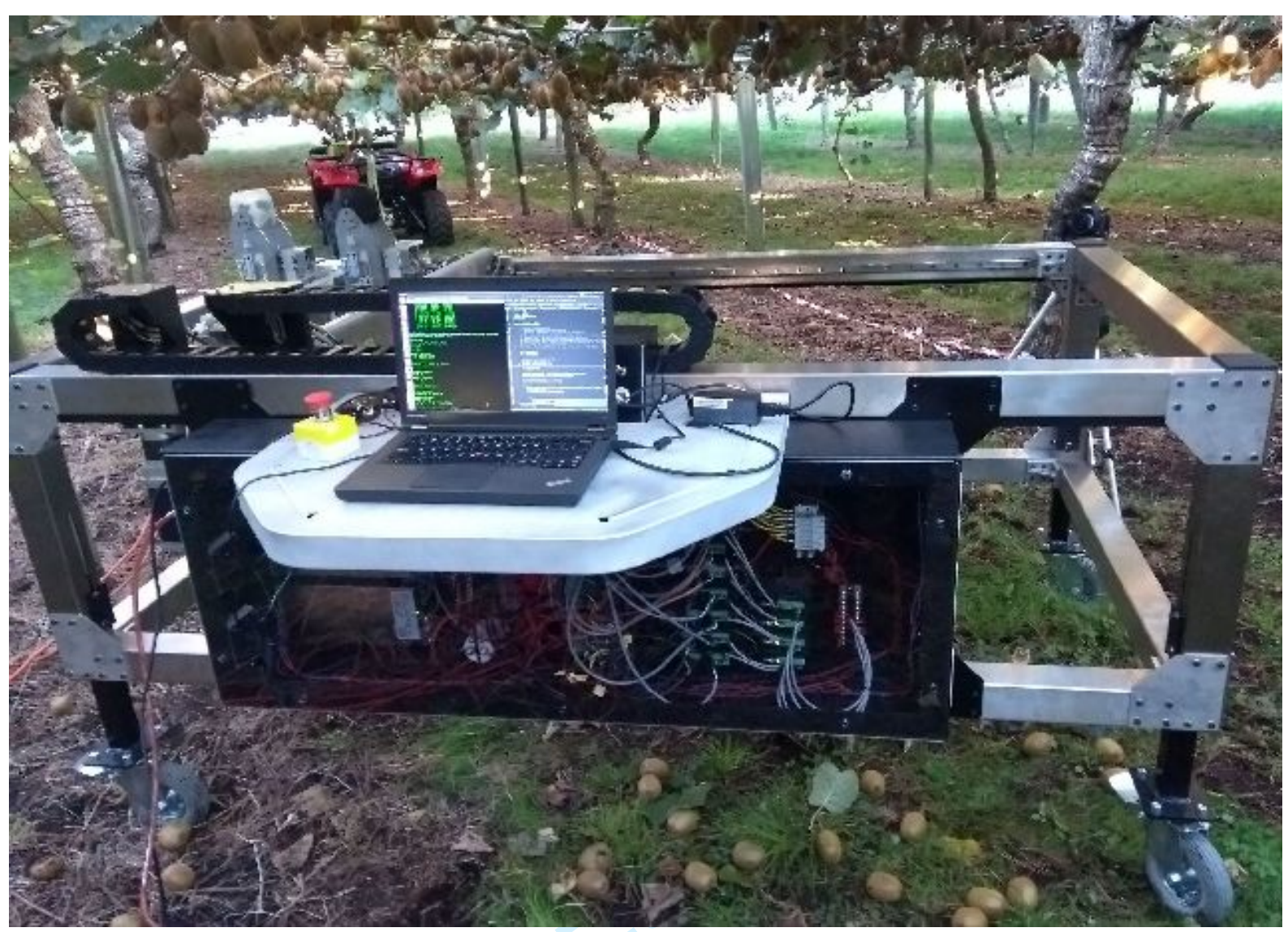

Figure 4. A Cartesian robot system with two arms in the orchard.

The robot system is positioned such that the maximum arm reachable height is just above the canopy top. The end-effector consists of a plastic sheath with a slightly conical upper edge and a beak-like shutter. Once the kiwifruit is enveloped by the sheath, the beak shutter actuates closed. The end-effector assembly rotates with fruit inside and then the manipulator retracts the end-effector downwards. These three steps are illustrated in Figure 5. 


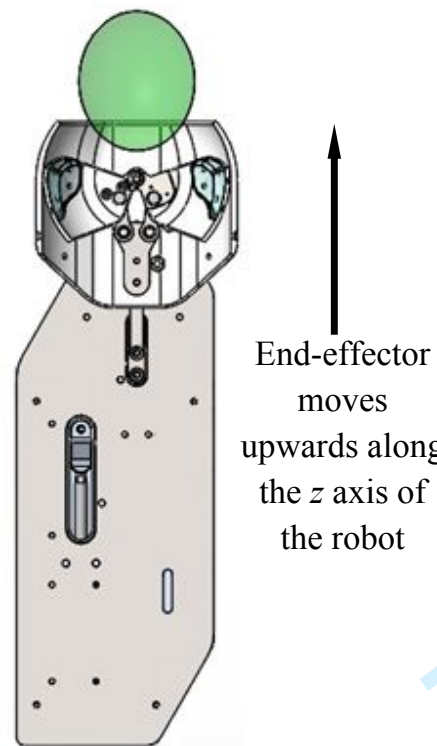

(a) The kiwifruit (green) is about to be enveloped.

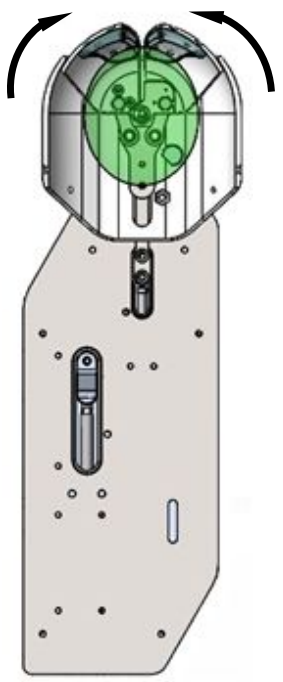

(b) The shutter is closed.

Figure 5. The operations of the end-effector.

As kiwifruit are grown on pergola frames and hang down vertically, the end-effector attached to the Cartesian robot approaches the fruit from the bottom vertically in the $z$ direction as shown in Figure 6. Furthermore, kiwifruit from the early-maturing orchards has been picked for early shipments, hence, all the fruit will be harvested and there is no concern for unripe fruit avoidance in the end-effector path. The grasping success rate of this end-effector is high as the inference of fruit poses (which is almost vertically oriented) is ignored.

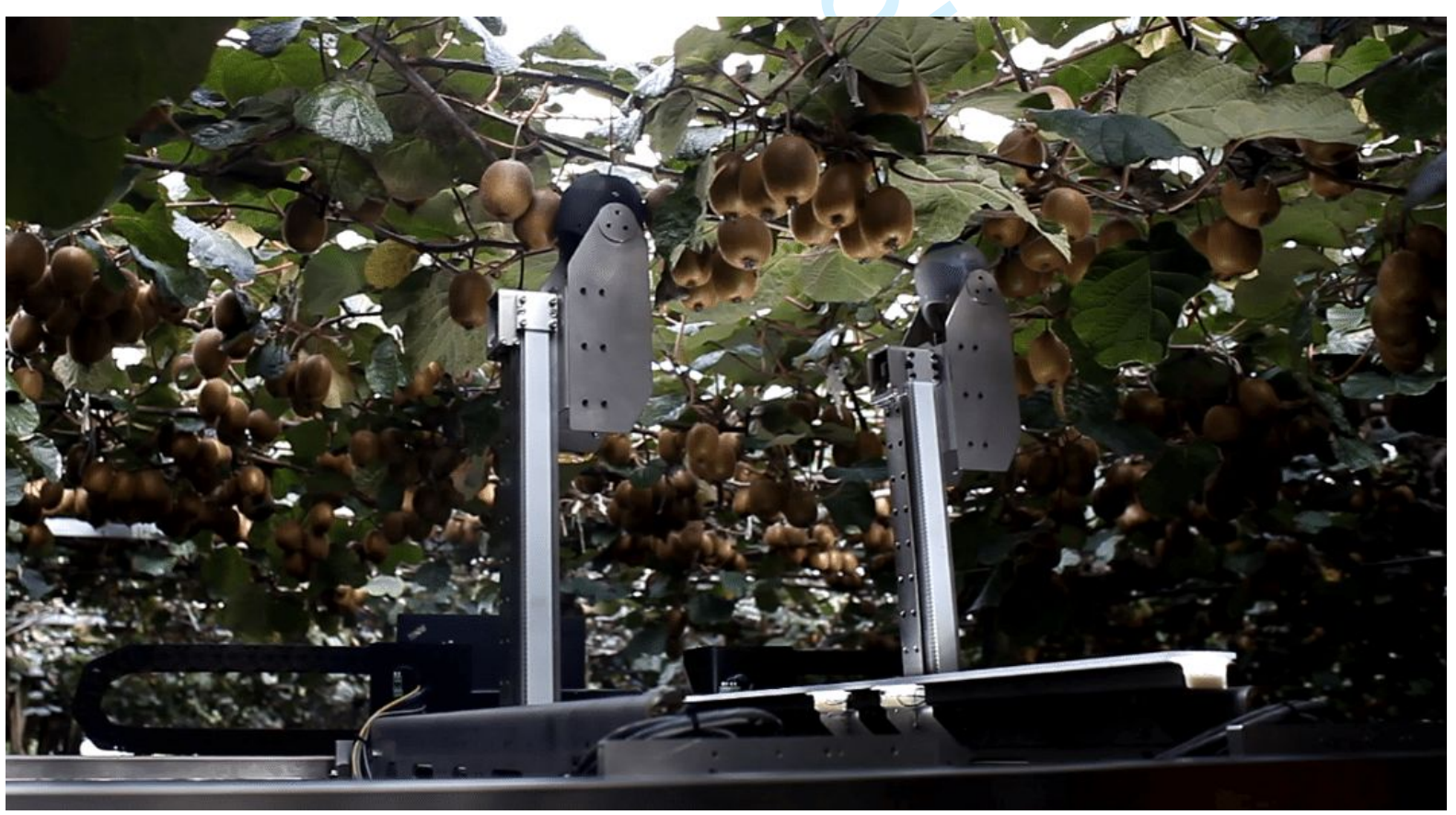

Figure 6. The end-effectors are harvesting the kiwifruit. 
The kiwifruit harvesting performance is evaluated in ten steps, five from the Batemans orchard and five from the Newnham orchard. Both orchards grow Hayward strain kiwifruit with a pergola style located in Tauranga, New Zealand.

The performance of the robot is measured in two perspectives, which are the success rate and the harvest cycle time. Success rate is the ratio of number of fruits harvested to all fruit in the canopy during a specific step. This also dictates how many fruit can be physically reached and successfully harvested by the end-effector with the required dexterity.

It is assumed that all harvested fruit are non-damaged as an optimal case scenario and instead focus will be made toward the knocking or dropping of fruit as part of the end-effector detachment process. All kiwifruit, which are knocked out of the canopy or dropped by the end-effector, are considered rejects in industry; thus, they are considered damaged fruit in this evaluation.

The harvest cycle time is obtained by equation (2) with average measured values of time for moving the robot between steps $\left(t_{\text {move }}\right)$, time for the vision system to locate the fruit $\left(t_{\text {locate }}\right)$, time for the robot to move between fruit harvesting $\left(t_{s u b-s t e p}\right)$ and fruit density per step $(\rho)$.

\section{Results}

The robot system for kiwifruit harvesting is a cooperative application where the robot arms work together to perform the harvesting task step by step. All the fruit in the canopy are reachable and will be harvested if they are within the resultant robot arms workspaces in the current step. Those outside the workspace are unreachable. However, these unreachable fruit are also located by the vision system as the portion of canopy captured by the camera is larger than the workspace of robot. Hence, they must be eliminated from the located fruit list before the fruit are scheduled to be harvested. These fruit will be harvested in the other steps.

Table 1 shows the success rate across the 10 steps. Of the fruit that are attempted, on average $77 \%$ are successfully harvested and $12 \%$ are dropped. These fruit are mainly knocked off by the end-effector. Some fruit are missed due to the shifting of fruit position when their neighbouring fruit are harvested within a cluster.

Table 1. The success rate of kiwifruit harvesting across 10 steps

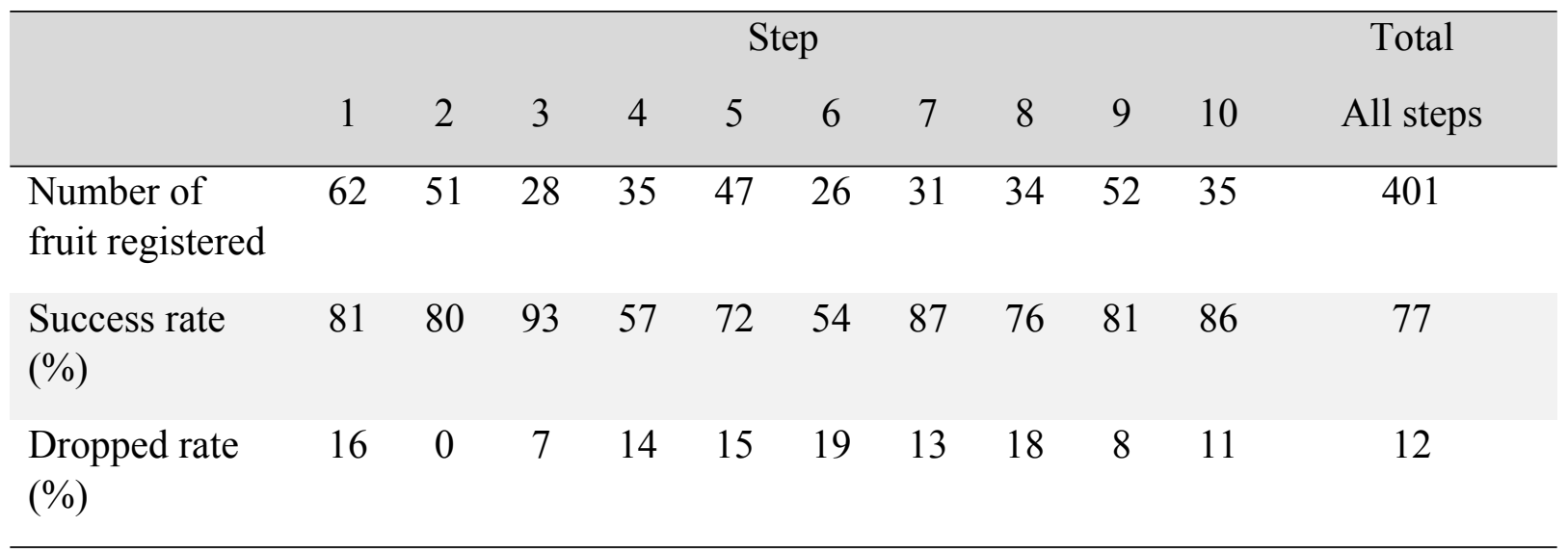

The average volumetric density of fruit within these ten steps is $137 \mathrm{fruit} / \mathrm{m}^{3}$. 
The average of recorded time to advance between steps and locate kiwifruit $\left(t_{\text {move }}+t_{\text {locate }}\right)$ is 3 minutes and the common sub-step time $\left(t_{\text {sub-step }}\right)$ is $2 \mathrm{~s}$.

Combining these variables and assuming that both robot arms share the same amount of work (that is $\left.W_{D}=1\right)$, the average harvest cycle time for the two-arm Cartesian robot $\left(t_{H C T}\right)$ in these ten steps is approximately $6.8 \mathrm{~s}$.

\section{Discussion}

The harvest cycle time is reduced if the robot has a large step advance volume. Hence, the workspace geometry is one of the key factors to determine if a Cartesian robot is more effective than an articulated robot for kiwifruit harvesting.

As a case study, the workspace of an articulated robot system with two arms is analysed by comparing to the Cartesian robot system. The articulated robot used is RA605 series from Hiwin Corporation (Hiwin 2020). This is a commercially available industrial robot for generic application. Although it is not specifically for outdoor kiwifruit harvesting application, its workspace geometry is irregular due to its articulated configuration. The comparison is to investigate the effect of workspace geometry on the number of steps required to cover the canopy.

The robot system comprises two articulated robot arms which are evenly spaced $325 \mathrm{~mm}$ across the width. The harvester is approximately $838 \mathrm{~mm}$ from the ground and is able to reach a maximum height of $1869.75 \mathrm{~mm}$ for picking the kiwifruit. The configuration and workspace of the articulated robot system are plotted in Figure 7. The dimensions can be obtained from the website of Hiwin Corporation.

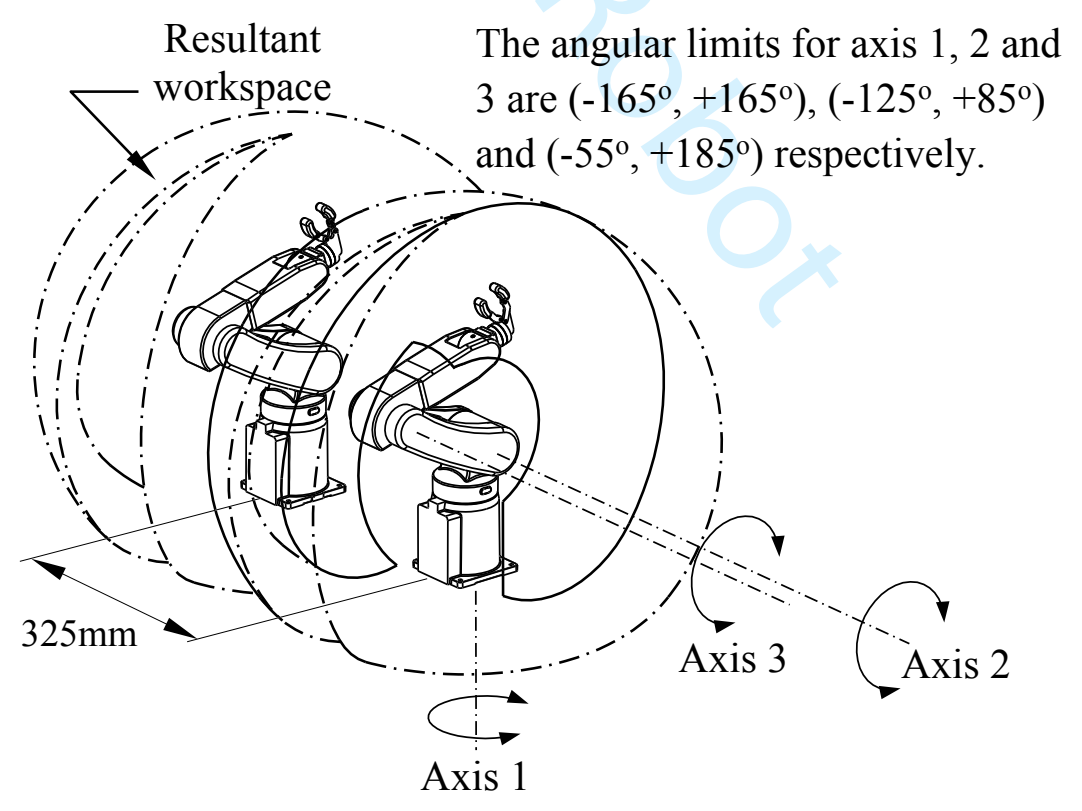

Figure 7. An articulated robot system with two arms and its resultant workspace.

The harvestable volume and step advance volume of both robot systems are illustrated in Figure 8 . The canopy volume is assumed to span $300 \mathrm{~mm}$ in the vertical $z$ dimension. The $x, y$ 
canopy dimensions span the array row width and row length respectively. The harvestable volume and step advance volume of a Cartesian robot system are regular since it has three prismatic joints along its $x, y$ and $z$ axis. Conversely, the geometry of harvestable volume and step advance volume of an articulated robot system are irregular due to the rotational axes.

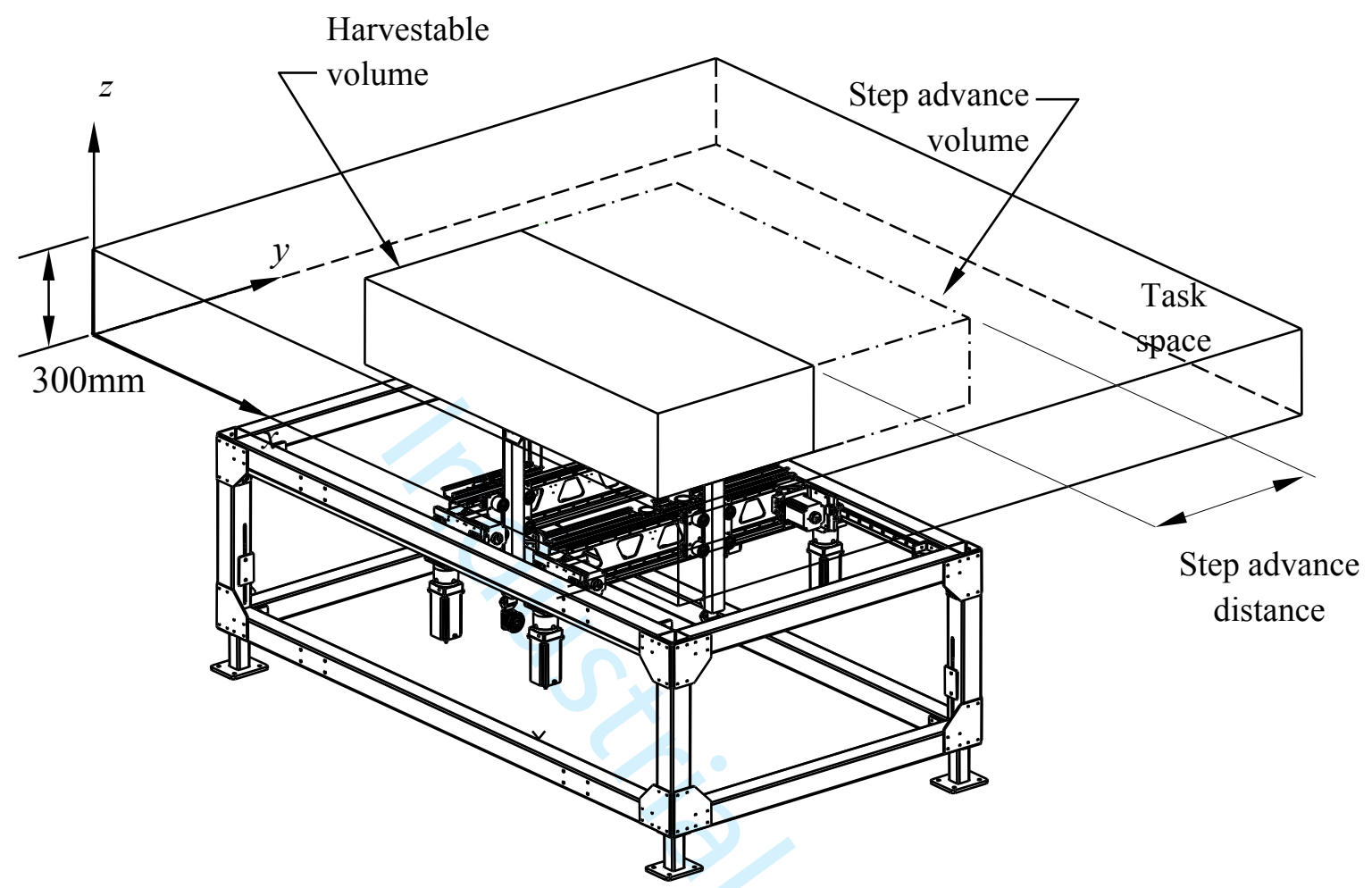

(a) Cartesian robot system.

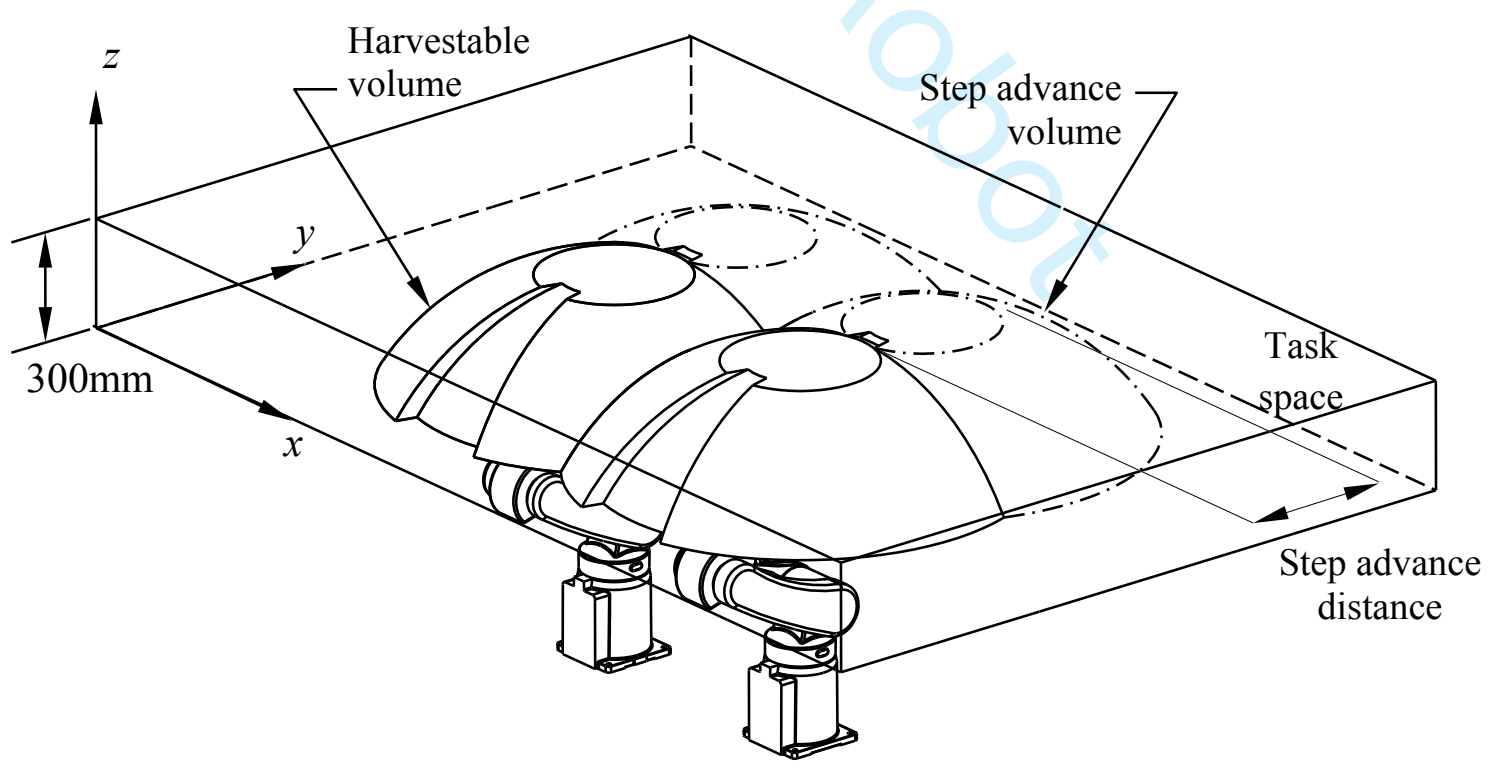

(b) Articulated robot system.

Figure 8 . The harvestable and step advance volume of the robot systems. 
The kiwifruit locations of the first five steps (tabulated in table 1) are plotted in Figure 9 with both robot systems to simulate the harvesting tasks.

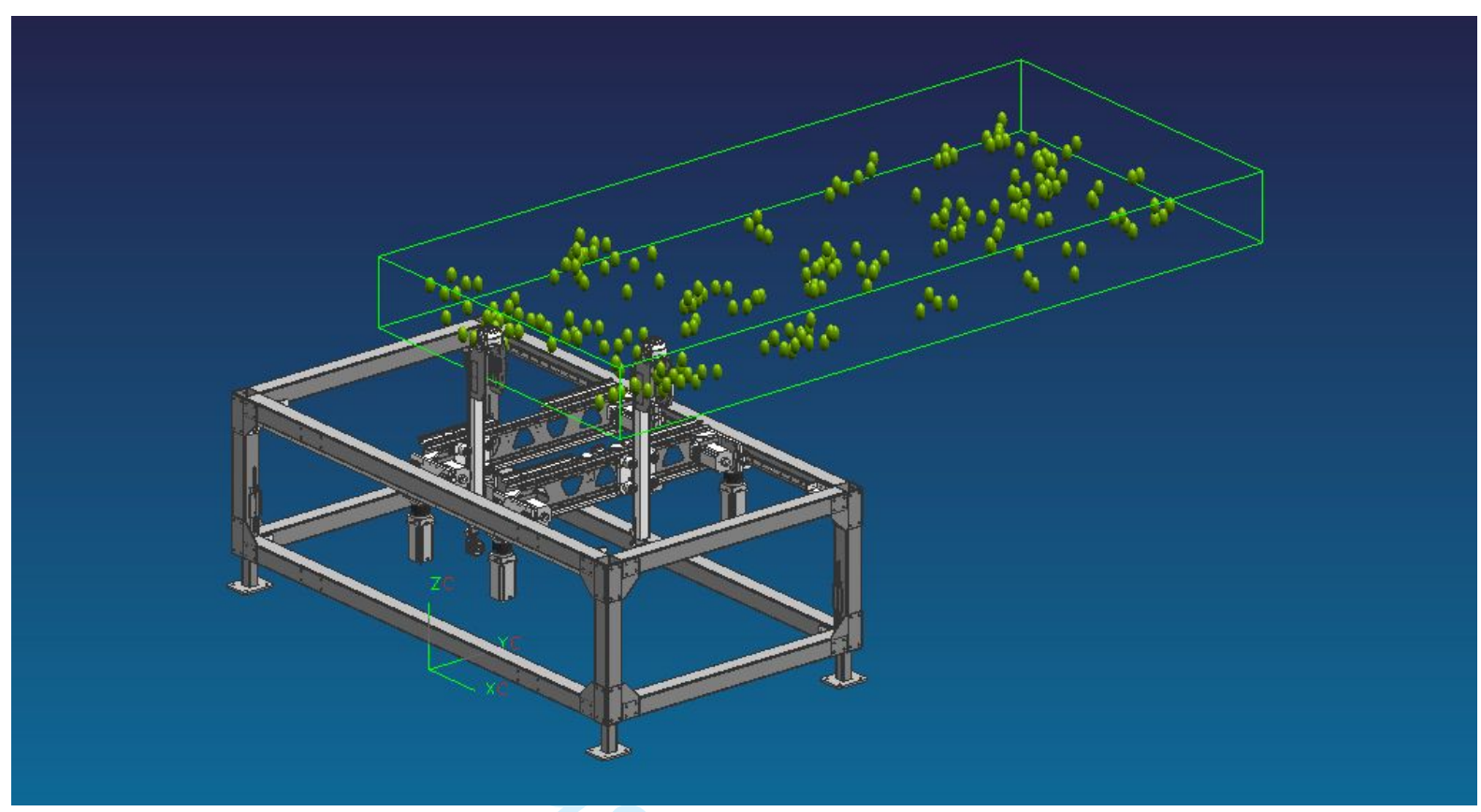

(a) Cartesian robot system

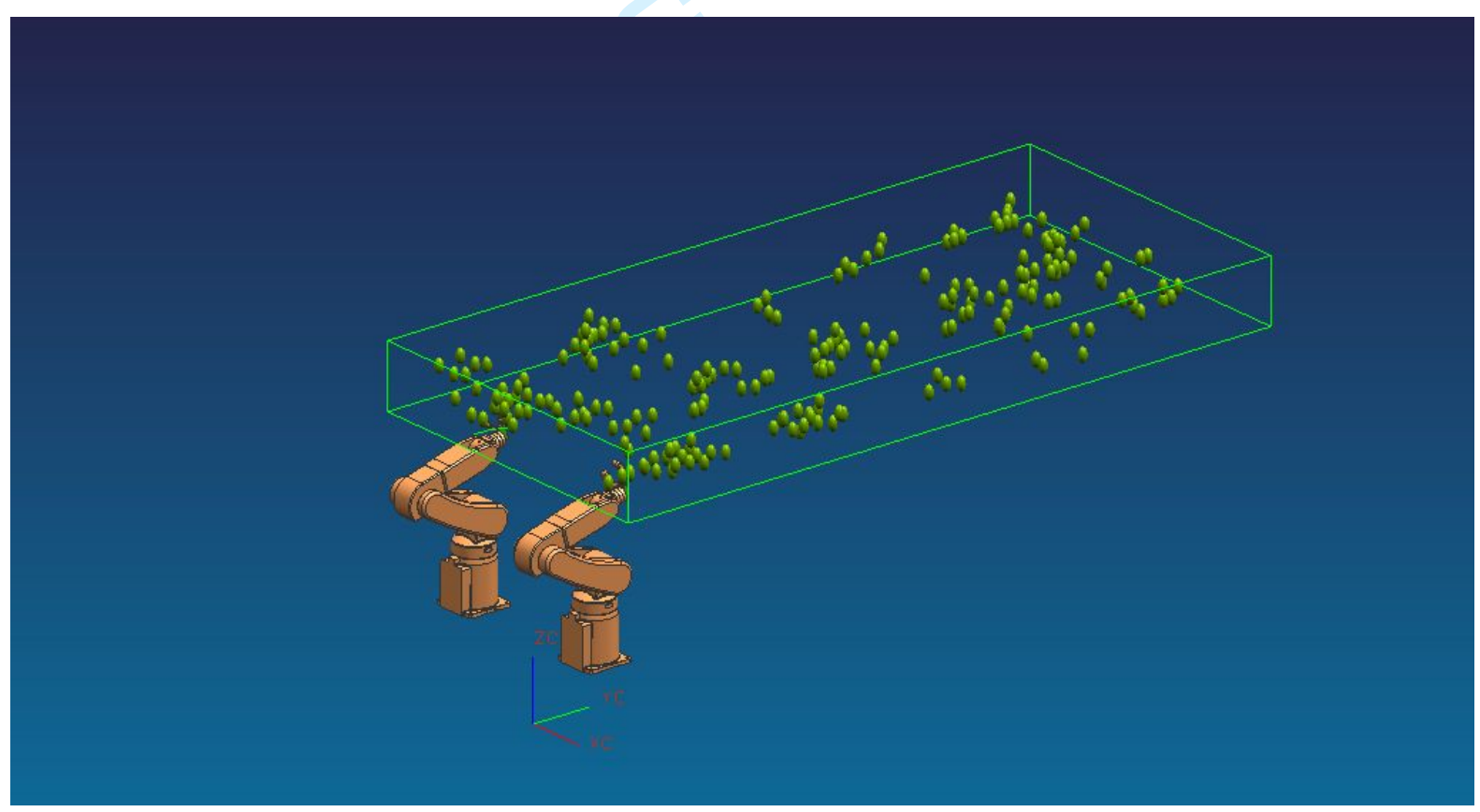

(b) Articulated robot system

Figure 9. Harvesting simulation.

The fruit in the canopy are partitioned into steps based on these two robot system configurations. Figure 10 depicts the number of steps required to complete the harvesting. 


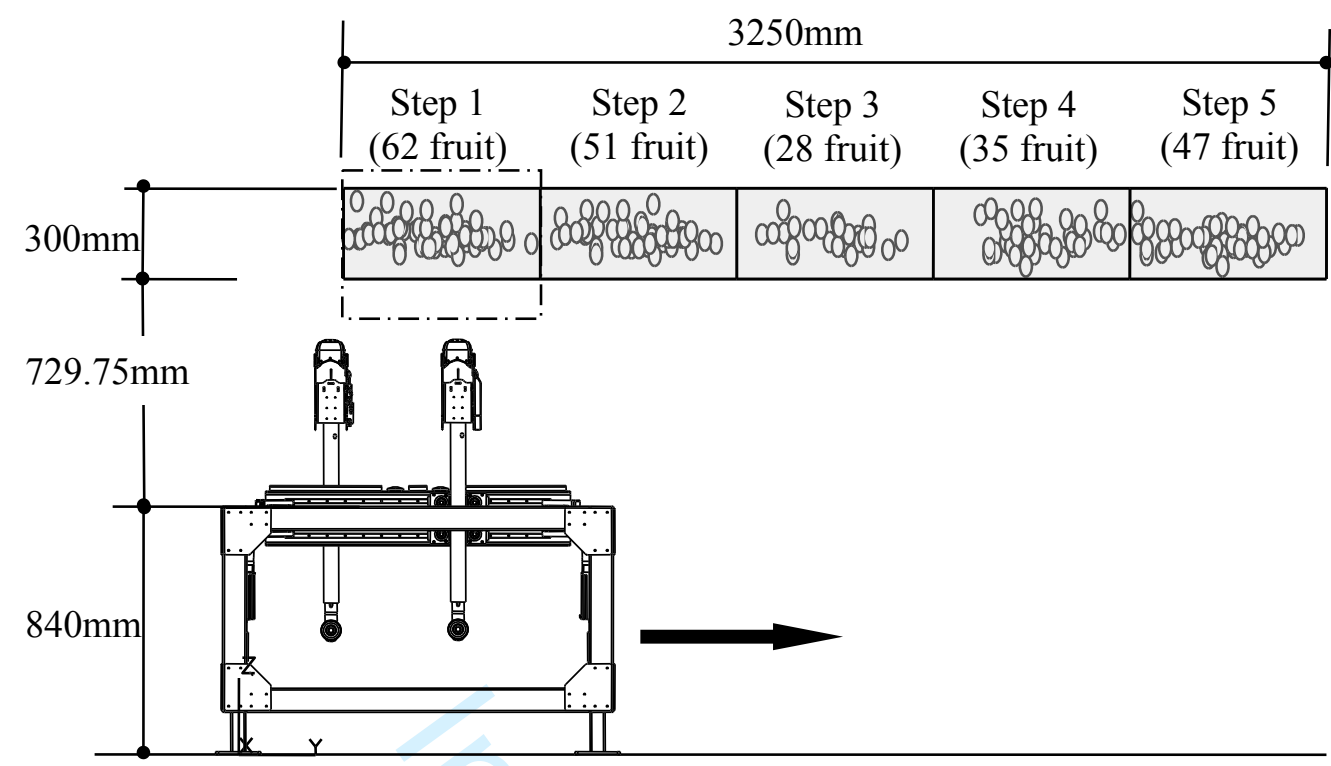

(a) Cartesian robot system

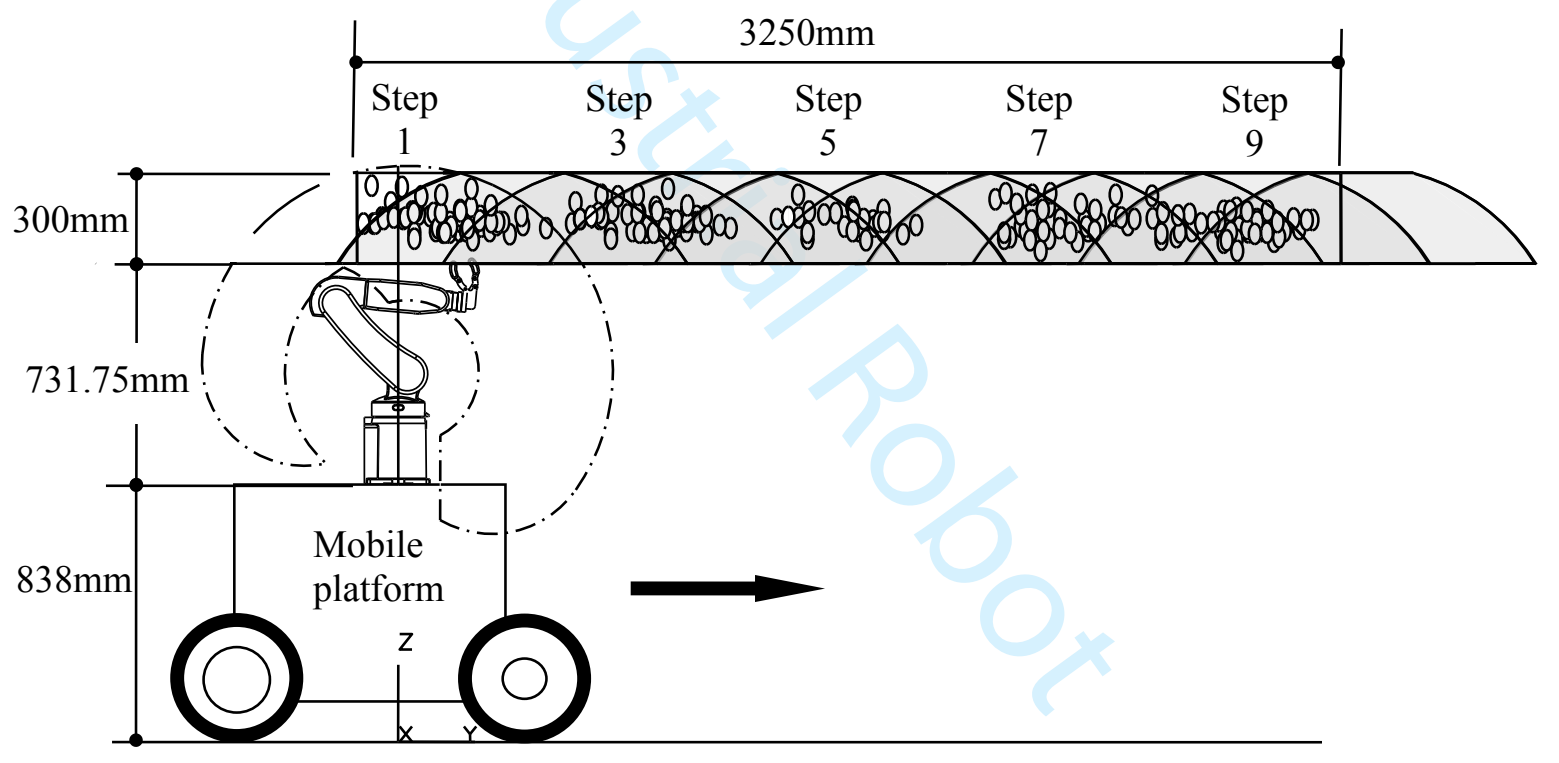

(b) Articulated robot system

Figure 10. The canopy covered by the harvesting steps.

The workspace volume analysis is tabulated in table 2 . 
Table 2. Workspace volume analysis between the articulated and Cartesian robot system.

\begin{tabular}{lcc}
\hline & Cartesian robot system & Articulated robot system \\
\hline No of steps & 5 & 9 \\
Workspace volume $\left(\mathrm{m}^{3}\right)$ & 0.439 & 2.15 \\
Harvestable volume $\left(\mathrm{m}^{3}\right)$ & 0.293 & 0.348 \\
Step advance volume $\left(\mathrm{m}^{3}\right)$ & 0.293 & 0.148 \\
Workspace efficiency $\left(=\frac{V_{a}}{V_{h}}\right)$ & $100 \%$ & $42.529 \%$ \\
\hline
\end{tabular}

The articulated robot system requires 9 steps to complete the harvesting while the Cartesian robot system only needs 5 steps. Despite the workspace volume of the articulated robot system is much larger than that of the Cartesian robot system $\left(2.15 \mathrm{~m}^{3} \mathrm{vs} 0.439 \mathrm{~m}^{3}\right)$, the harvestable volumes are close to each other $\left(0.348 \mathrm{~m}^{3} \mathrm{vs} 0.293 \mathrm{~m}^{3}\right)$. This is because the task space locates right above the robot systems. However, the difference in step advance volume is large $\left(0.148 \mathrm{~m}^{3}\right.$ vs $\left.0.293 \mathrm{~m}^{3}\right)$.

The irregular workspace geometry of an articulated robot means that the actual step advance distance is shorter. This implies that the articulated robot system moves, detects and locates fruit more frequently. Thus, operational downtime (such as time for the robot system to move and vision system to locate the fruit) increases.

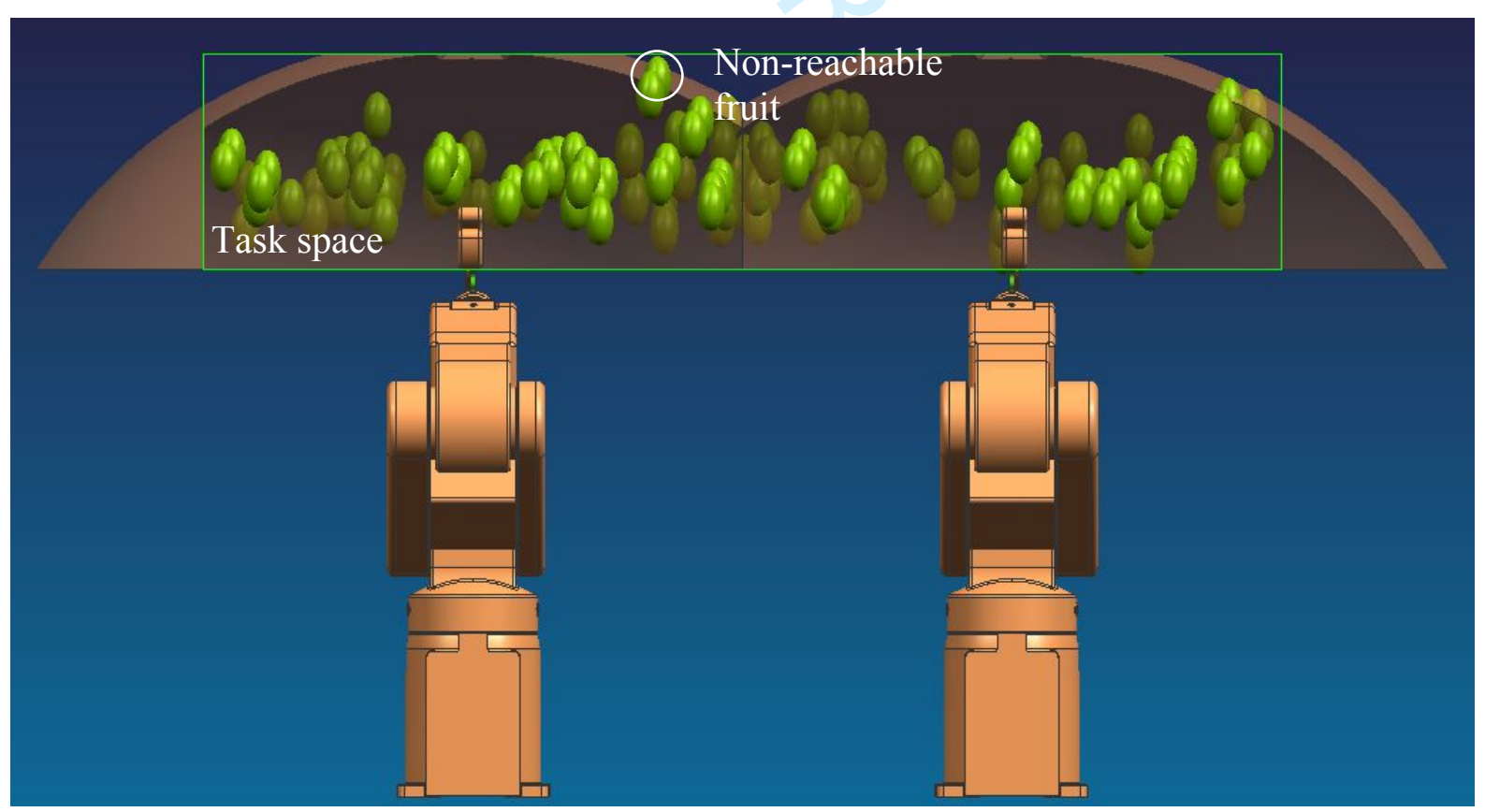

Figure 11. A non-reachable fruit in the canopy. 
In fact, nine steps of harvesting tasks using the articulated robots do not completely cover the task space as shown in Figure 11. One fruit is not harvested in this simulation as its location (which is the centre of fruit) is outside the step advance volume. This implies that the articulated robots needs to be positioned closer to each other due to its irregular shape harvestable and step-advance volume.

Under the assumption that both robot systems have the same mobile platform, same vision system for locating fruit, same sub-step time for harvesting and the work distribution among the arms are equally balanced $\left(W_{D}=1\right)$, the estimated harvest cycle time for the robot systems are tabulated in Table 3.

Table 3. The estimated harvest cycle time for both Cartesian and articulated robot systems.

\begin{tabular}{lccc}
\hline & $\frac{t_{\text {move }}+t_{\text {locate }}}{\rho \cdot V_{a}}$ & $\frac{t_{\text {sub }}-\text { step }}{N_{\text {arms }} \cdot W_{D}}$ & Estimated $t_{H C T}(\mathrm{~s})$ \\
\hline $\begin{array}{l}\text { Cartesian robot } \\
\text { system }\end{array}$ & $\frac{180}{137 \times 0.293}=4.48$ & $\frac{2}{2 \times 1}=1$ & 5.48 \\
$\begin{array}{l}\text { Articulated robot } \\
\text { system }\end{array}$ & $\frac{180}{137 \times 0.148}=8.88$ & $\frac{2}{2 \times 1}=1$ & 9.88 \\
\hline
\end{tabular}

The estimated harvest cycle time for articulated robot system is approximately $4 \mathrm{~s}$ more than that of the Cartesian robot system. However, the vertical rotation axis of the articulated robot system should yield a more efficient lateral movement of the end-effector than that of the Cartesian robot system, which implies a decrement in the sub-step time $t_{\text {sub-step. This }}$ efficient lateral movement of end-effector is significant if the time for moving between steps and locating fruit are reduced to a comparable value of the term $\frac{t_{\text {sub }- \text { step }}}{N_{\text {arms }} \cdot W_{D}}$. These are the future improvements for the harvesting task in orchard.

These harvest cycle times are obtained under the assumption that the work distribution is uniform $\left(W_{D}=1\right)$. In fact, the work distribution relates to the kiwifruit distribution and the fruit allocation to the robot arm by the fruit scheduler. The actual average work distribution for this Cartesian robot system is higher than that of the articulated robot system due to differences in configuration. The work distribution is discussed in another article (Josh et al 2020).

\section{Conclusion}

Multiple robot arm system should be employed for fruit harvesting in an orchard in order to raise the productivity. The contribution of this article is to pinpoint the fact that the workspace geometry of a robot system is an important factor to consider for determining the robot system configuration.

When the canopy is much larger than the resultant workspace of a multiple robot arm system, the harvesting task has to be performed step by step. The union of workspaces in each step should cover the entire canopy. If the workspace geometry of the robot system conforms to the geometry of canopy volume, the step advanced distance can be large. This implies a 
decrease in the number of steps and harvest cycle time. As a result, the harvesting task is more efficient.

Most of the kiwifruit orchards are of pergola style so that the kiwifruit locations can be described by a Cartesian coordinate system. A Cartesian robot system yields a workspace of rectangular shape, which conforms to the canopy volume. This implies no overlapping of harvestable volume between steps. Hence, the step advance volume can be as large as the harvestable volume. Conversely, the step advance volume of an articulated robot is less than its harvestable volume due to its irregular workspace geometry. As a result, using a Cartesian robot system to harvest the kiwifruits in a canopy yields less steps and reduces the operational down time. Consequently, the economic benefit is raised.

\section{Reference}

Bac, C. W., Hemming, J., van Tuijl, B., Barth, R., Wais, E. and van Henten, E. J. (2017), "Performance evaluation of a harvesting robot for sweet pepper", Journal of Field Robotics, Vol. 34, pp. 123-1139.

Bac, C. W., van Henten, E. J., Hemming, J., and Edan, Y. (2014), "Harvesting robots for high-value crops: State-of-the-art review and challenges ahead", Journal of Field Robotics, Vol. 31, pp. 888-911.

Bachche, S. (2015), "Deliberation on design strategies of automatic harvesting systems: A survey”, Robotics, Vol. 4 No. 2, pp. 194-222.

Barnett, J. (2018), "Prismatic axis, differential-drive robotic kiwifruit harvester for reduced cycle time", Master of Engineering Thesis. University of Waikato.

Barnett, J., Duke, M., Au, C. and Lim, S. (2020), "Work distribution of multiple Cartesian robot arms for kiwifruit harvesting", Computers and Electronics in Agriculture, Vol. 169, doi.org/10.1016/j.compag.2019.105202

Baur, J. T. (2014), “Agricultural manipulators simulation, design and motion planning”, $P h D$ thesis, Technischen Universität München.

Baur, J. T., Pfaff, J., Ulbrich, H. and Villgrattner, T. (2012), "Design and development of a redundant modular multipurpose agricultural manipulator", in 2012 IEEE/ASME

International Conference on Advanced Intelligent Mechatronics (AIM), pp. 823-830.

Bloch, V., Bechar, A. and Degani, A. (2017), "Development of an environment characterization methodology for optimal design of an agricultural robot", Industrial Robot, Vol. 44 No. 1, pp. 94-103.

Foglia, M. M. and Reina, G. (2006), “Agricultural robot for radicchio harvesting”, Journal of Field Robotics, Vol. 23 No. 67, pp. 363-377.

Han, S., Xueyan, S., Tiezhong, Z., Bin, Z. and Liming, X. (2007), “Design optimisation and simulation of structure parameters of an eggplant picking robot", New Zealand Journal of Agricultural Research, Vol. 50. pp. 959-964. 
Hayashi, S., Yamamoto, S., Saito, S., Ochiai, Y., Kamata, J., Kurita, M. and Yamamoto K. (2014), "Field operation of a movable strawberry-harvesting robot using a travel platform", Japan Agricultural Research Quarterly, Vol. 48 No. 3, pp. 307-316.

Henten, E. J. V., Van’t Slot, D. A. , Hol, C. W. J. and Van Willigenburg, L. G. (2009), "Optimal manipulator design for a cucumber harvesting robot" Computers and Electronics in Agriculture, Vol. 65 No. 2, pp. 247-257.

Hiwin Corporation accessed in February 2020 https://www.hiwin.com/articulatedrobots.html).

Kapach, K., Barnea, E., Mairon, R., Edan, Y. and Shahar, O. B. (2012), “Computer vision for fruit harvesting robots-state of the art and challenges ahead", International Journal of Computational Vision and Robotics, Vol. 3 No.1-2, pp. 4-34.

Li, P., Lee, S. H. and Hsu, H. Y. (2011), "Review on fruit harvesting method for potential use of automatic fruit harvesting systems", Procedia Engineering, Vol. 23 No. , pp. 351-366.

Mu L., Cui, G.,Liu, Y.,Cui, Y., Fu, L. and Gejima, Y. (2020), "Design and simulation of an integrated end-effector for picking kiwifruit by robot", Information Processing in Agriculture, Vol. 7 No. 58-71.

Sarig, Y. (1993), "Robotics of fruit harvesting: A state-of-the-art review", Journal of Agricultural Engineering Research, Vol. 54, pp. 265-280.

Scarfe, A. J., Flemmer, R. C., Bakker, H. H. and Flemmer, C. L. (2009) "Development of an autonomous kiwifruit picking robot" 4th International Conference on Autonomous Robots and Agents, Wellington, 2009, pp. 380-384.

Silwal, A., Davidson, J., Karkee, M., Mo, C., Davidson, J. R., Zhang, Q. and Lewis, K. (2017), "Design, integration, and field evaluation of a robotic apple harvester", Journal of Field Robotics, Vol. 34 No. 6, pp. 1140-1159.

van Henten, E. J., Hemming, J., van Tuijl, B. A. J., Kornet, J., Meuleman, J., Bontsema, J. and van Os, E. A. (2002), "An autonomous robot for harvesting cucumbers in greenhouses", Autonomous Robots, Vol. 13 No. 3, pp. 241-258.

Wang, L., Zhao, B., Fan, J., Hu, X., Wei, S., Li, Y., Zhou, Q. and Wei, C. (2017), "Development of a tomato harvesting robot used in green-house", International Journal of Agricultural and Biological Engineering, Vol. 10, pp.140-149.

Williams, H., Jones, M. H., Nejati, M., Bell, J., Penhall, N., Seok, H. A., Lim, J., MacDonald, B., Seabright, M., Barnett, J., Duke, M., and Scarfe, A. (2019), "Robotic kiwifruit harvesting using machine vision, convolution neural networks, and robotic arms", Biosystems Engineering, Vol. 181 No. pp. 140-156. 